\title{
Commentary: The evolving management of primary graft dysfunction in heart transplantation
}

John W. C. Entwistle III, MD, PhD

\author{
From the Division of Cardiac Surgery, Department of Surgery, Thomas Jefferson University, Philadelphia, Pa. \\ Disclosures: Author has nothing to disclose with regard to commercial support. \\ Received for publication March 7, 2019; accepted for publication March 8, 2019; available ahead of print April \\ $30,2019$. \\ Address for reprints: John W. C. Entwistle III, MD, PhD, 1025 Walnut St, Suite 607, College Building, Philadel- \\ phia, PA 19107 (E-mail: john.entwistle@jefferson.edu). \\ J Thorac Cardiovasc Surg 2019;158:1587-8 \\ 0022-5223/\$36.00 \\ Copyright (c) 2019 by The American Association for Thoracic Surgery \\ https://doi.org/10.1016/j.jtcvs.2019.03.083
}

Just over 50 years ago, the first heart transplant was performed. Long-term survival was uncommon until the advent of cyclosporine (INN ciclosporin) nearly 35 years ago. Since then, there have been many changes in the field of heart transplantation, yet primary graft dysfunction (PGD) persists and is a significant cause of early death after heart transplantation. In patients with PGD, the cause of death is often multiorgan failure resulting from the poor perfusion of the peripheral organs. In patients with PGD, the primary goal is to support the hemodynamics until the heart recovers so that multiorgan failure does not occur.

In this issue of the Journal, DeRoo and colleagues ${ }^{1}$ present their experience at a single institution over a 7-year period with the use of extracorporeal membrane oxygenation (ECMO) to support patients who have PGD develop after heart transplantation. There were 2 findings in this article that are particularly interesting. First, PGD is not a rare event. PGD severe enough to qualify for ECMO support was seen in $10.5 \%$ of patients. Second, prompt initiation of ECMO support produced a nonsignificant survival advantage, with $90 \%$ survival at 1 year, compared with $67 \%$ after conservative ECMO initiation.

This current article of DeRoo and colleagues ${ }^{1}$ follows a recent publication by the same group, ${ }^{2}$ which compared patients with PGD who were supported with temporary ventricular assist devices with those supported with ECMO. This article showed that there were fewer patients in the ECMO group who required reexploration for bleeding or renal replacement therapy, and there was also a nonsignificant higher percentage of survival in the ECMO group. There was some overlap in the dates of these 2 studies, but most of the patients supported by ECMO in the earlier study were in the conservative ECMO group in the current study. When taken together, these studies suggest that ECMO support is superior to temporary ventricular assist device support in the setting of PGD, and that prompt initiation of ECMO is superior to a more conservative approach. This likely reflects the basic concept that prevention of

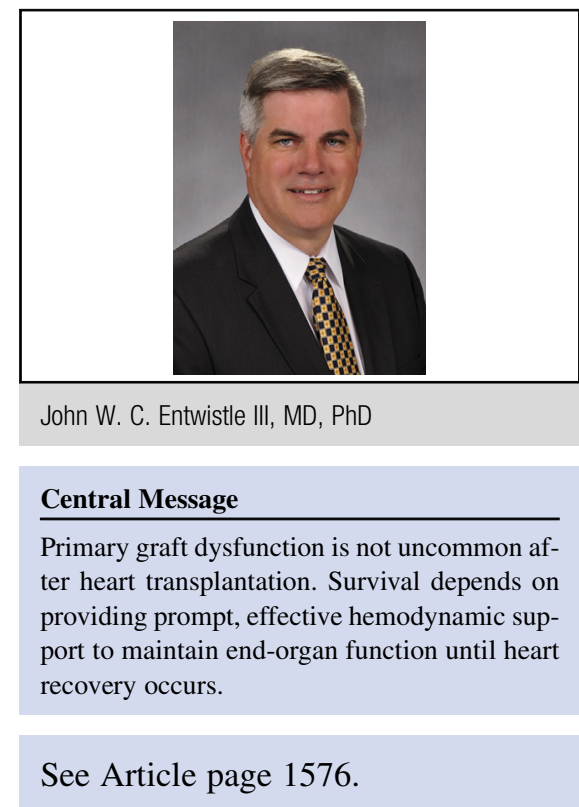

multiorgan failure is the key to survival, which requires that effective support be initiated before the end organs begin to suffer significant injury.

Caution must be exercised, however, when interpreting these results. It is highly unlikely that the choice of support methods and the timing of support were the only differences in the management of heart transplant recipients during the time periods of the 2 studies. In the current study of DeRoo and colleagues, ${ }^{1}$ there are other factors that could account for some of the improvement seen in the prompt ECMO group. More patients in this cohort received a heart from a male donor, the ejection fraction of the donor heart was higher, and the ischemic time was shorter. Although the conclusions of the studies make sense-prompt and complete hemodynamic support will maintain function of the other organs while the heart has time to recover-it is possible that other changes in donor or recipient management or selection may have significant effects as well.

There are 3 non-mutually exclusive strategies to minimize the effects of PGD. First, we can be very restrictive in the hearts that we select for our recipients, hoping to minimize the occurrence of PGD. If we do this, however, we will end up with more people dying of heart failure and many more wasted organs. Second, we can look for the underlying cause of PGD in an effort to prevent it from occurring. While this is a noble goal, we have been unsuccessful in achieving it thus far. Third, we can anticipate 
that PGD will occur and manage it to the best of our abilities. As shown in this article by DeRoo and colleagues, ${ }^{1}$ ECMO has worked well for this transplant program and their patients. ECMO may not be the final answer, and it may not be the answer for all transplant programs, but what we do know is that every heart transplant program is going to face PGD. A program that is prepared, recognizes PGD early, and institutes aggressive treatment promptly will have better outcomes than those centers that do not plan ahead and make every effort to avoid using mechanical support devices for these patients. The use of temporary ventricular support devices or ECMO to support a patient with PGD should not be looked at as a failure of the operation, but rather as an appropriate way to manage a known complication of the procedure on which we do not yet have a firm handle. Each program should evaluate its resources and capabilities and develop algorithms and policies that leverage these resources for the management of PGD such that when it occurs, the management can be prompt and efficient. In doing so, survival after PGD may be maximized, to the benefit of our programs and of the patients who have put their trust in us.

\section{References}

1. DeRoo SC, Takayama H, Nemeth S, Garan AR, Kurlansky P, Restaino S, et al. Extracorporeal membrane oxygenation for primary graft dysfunction after heart transplant. J Thorac Cardiovasc Surg. 2019;158:1576-84.e3.

2. Takeda K, Li B, Garan AR, Topkara VK, Han J, Colombo PC, et al. Improved outcomes from extracorporeal membrane oxygenation versus ventricular assist device temporary support of primary graft dysfunction in heart transplant. J Heart Lung Transplant. 2017;36:650-6. 